while of course all the septic decomposing contents of the intestines are completely washed out. If such a line of treatment has been proved beneficial in septic peritonitis, it should surely prove more so still in acute obstruction, for in this latter, after the relief of the obstruction, death is almost. always due to the absorption of the poisonous products from the intestine. Prevent this by removing them completely as can be done by irrigation, and many lives should be saved.

\section{ON CONGENITAL HOUR-GLASS STOMACH.}

BY W. F. BROOK, F.R.C.S. Senior Surgeon, Swansea Hospital.

As Mr. Moynihan has shown in his able and most interesting paper on hour-glass stomach, published in the BrITIs: Medical Journal of February 2oth, this condition is almost invariably acquired; and no doubt many surgeons, bearing in mind their own experience, will be inclined to agree with him that its congenital origin is probably a mpth.

This would certainly have been my belief after reading his paper had it not been for a case which I met with in Jun last. Prior to this, so far as my own experience went (but I do not for a moment suggest that it had been sufficient to warrant the formation of any independent conclusion), every case of hour-glass stomach which I had seen, whethe on the operating table or post mortem, bore ample evidence of having originated in one of the three conditions which Mr. Moynihan mentions, but especially malignant disease and chronic ulceration. Where the latter had been the cause I had on two occasions met with perforation at the isthmus into the general peritoneal cavity. The first was in one of three cases ending fatally out of nine in which I had operated for perforate gastric ulcer. The other occurred in a patient while slowly recovering in the Swansea Hospital after an ovariotomy in which persistent oozing from the raw surfaces resulting from separation of very extensive adhesions had necessitated packing the whole pelvis with gauze. The patient died within three hours of the onset of sym ptoms, and before the house-surgeon had realized what had happened. The posterior wall of the constriction, which admitted three fingers, consisted of an old ulcer whose base was formed by adherent and eroded pancreas, the perforation being in front.

The following case however is, I think, clearly of congenital origin. I saw the patient with Dr. E. B. Evans, of Swansea. He administered the anaesthetic at the operation while his son, Surgeon Alban Evans, R.N., formerly house-surgeon at the Swansea Hospital, kindly assisted me. Unfortunately, no necropsy was obtained.

History.-The patient was a school-mistress, aged 5o. She had been giable since girlhood to pain after food at no fixed interval. followed and relieved by vomiting. At times she was very ill and unable to continue her occupation. Notably was this the case in 1882 . In the early part of 1902 she was much reduced and incapacitated by incessant vomiting; but between September, r902, and the spring of $x_{903}$, she had been very much better and had gained weight. From this time she commenced to go down-hill again, losing flesh, the pain and vomiting becoming worse and worse, until she finally took to bed early in June. There was no history of haematemesis or melaena.

Condition when First Seen.-When I saw her she was extremely maciated, everything, even peptonized food, being vomited, and she was rapidfy going from bad to worse. The stomach did not appear markedly dilated. The diagnosis lay between pyloric or hour-glass stenosis. The general enfeeblement was so marked that it was decided before operating to endeavour to pick up the strength by rectal feeding. Under this treatment the' vomiting ceased, the pulse became stronge and less rapid, and the general condition greatly improved, and had the operation been done at the end of five days it might have had a successful issue. On the seventh day the enemata were returned and retching and vomiting recurred, and it was decided to operate without further loss of time.

Operation and Result.-Upon opening the abdomen on July ist the stomach, which was unusually thin-walled and could be easily with drawn, was found to be divided into two pouches of about equal size by a narrow constriction. The peritoneum covering the isthmus was free from adhesions both in front and behind. It was as transparent, glossy and free from thickening as that covering either pouch and the omenta continuous with it above and below showed no sign of puckering. Palpated between the finger and thumb it showed no more thickening than a fold of the stomach picked up at any other spot. The pylorus and both pouches were free from thickening and showed no externa indication of chronic ulceration. Upon incising the isthmus, which would admit of a No. 7 or 8 catheter, both the mucous membrane lining it and that of either pouch to a distance of some two inches, was readily and carefully inspected. It was soft and velvety throughout, and showed not the slightest sign of cicatrix. The operation of gastro- plasty was rapidly completed, but the patient unfortunately sank and died ten hours later.

It is obvious that so narrow a constriction in the stomach must be a very vulnerable spot, so that it is not. improbable that congenital hour-glass contraction may actually lead to ulceration, when traces of the latter, if found, would be liable to be wrongly interpreted as evidence of a pathological origin of the deformity. A case referred to by Messrs.-Robson and Moynihan, ${ }^{1}$ although quoted as an example of the way in which an hour-glass stomach of chronic inflammatory origin, unless very carefully examined, may appear to be congenital, would seem to admit of such an explanation.

I Robson and Moynihan, Diseases of the Stomach and Their Surgical Treatment, pp. 174-5.

\section{CASE OF CONGENITAL HYPERTROPHIC STENOSIS OF THE PYLORUS.}

By ARTHUR J. CLEVELAND, M.D.LOND., M.R.C.P. Norwich.

THERE is little doubt that this condition is much commoner than was at one time supposed, and in view of the successful results that have of late attended operations for its relief, it is important to record cases of the disease verified by actual examination, in the hope that by so doing early recognition, and consequently early interference, may become easier. Unfortunately the two chief symptoms, vomiting and constipation, are by no means rare in infants, and may be due to 1aulty diet, while the peristalsis and other conclusive evidence of a dilated stomach may, as in this case, only become obvious when the general condition of the child is too bad to enable an operation to offer much hope of success.

A male child was first seen by me when two months old, for vomiting, constipation, and wasting. He was a fine baby at birth, but when 14 days old began to vomit and suffer from constipation. He took the breast well but returned what he got immediately after finishing a feed-sometimes the vomit was large in amount, but food was never retained but vomited an hour or so later. The bowels were very obstinate in spite of treatment, being opened on an average once a week, and on one occasion no motion was passed for thirteen days. The child had wasted rapidly, and when I saw it was little more than skin and bone with a pinched face, depressed fontanelle, and feeble cry.

There was no abdominal distension, and beyond a considerable increase of stomach resonance both to direct and auscultatory percussion, there was nothing to confirm my suspicion of the actual condition. A week later well-marked peristalsis was visible from left to right over the upper part of the abdomen, and I elicited a succussion splash. I could not feel any lump in the region of the pylorus. The question of operation was discussed, as the diagnosis now appeared certain, but the general condition of the child was very bad, and the parents would not consent to what was rather a hopeless remedy. He died of exhaustion three weeks later, when 3 months old, the pertinacity with which he clung to life being all the more astonishing as during that time he had frequent fits, passing from one convulsion into another, according to the mother's account. I never saw the child in one of these fits, which from the mother's description I took to be tetany.

The necropsy was limited to the abdomen. The lower border of the stomach reached to the umbilicus, and the viscus oocupied the whole of the epigastric and left hypochondriac regions. The pylorus was hard and felt almos cartilaginous; it measured $\frac{8}{4}$ in. in length and was shaped like a bobbin, namely, with a constriction in the middle and a maximum circumference at either end of $1 \frac{7}{8} \mathrm{jn}$. It admitted an instrument with a circumference of $\frac{5}{8}$ in. The mucous membrane lining it was thrown into folds; there was no ufceration.

The stomach had lost its normal shape, its walls were thin and the mucous membrane smooth. The intestines appeared almost empty, and there was scarcely any fat to be seen on the child.

Microscopically the hypetrophy was mainly in the circular muscle coat, with some increase of fibrous tissue.

Médical Magistrate.-Dr. Wm. Henry Lewis, of Llansantffraid, has been appointed a Justice of the Peace for the County of Montgomery. 